\title{
ANÁLISIS ESTRUCTURAL DE LA FILOSOFÍA JURÍDICA HEGELIANA
}

STRUCTURAL ANALYSIS OF HEGELIAN LEGAL PHILOSOPHY

\author{
JUAN MANUEL ESPINOSA ARES \\ Universidad Nacional de Educación a Distancia
}

Recibido: $12 / 10 / 2018 \quad$ Aceptado: 22/01/2019

\section{RESUMEN}

El presente artículo pretende llevar a cabo un estudio estructural de la filosofía del derecho hegeliana. Mi intención es, por un lado, estudiar y criticar la lógica del proyecto filosófico-político hegeliano, y por otro, establecer sus vínculos con la filosofía moderna que le precede, en concreto con el idealismo trascendental kantiano

Palabras clave: ser, razón, univocidad, libertad, subjetividad, dialéctica, abstracción, espíritu absoluto, derechos subjetivos, contrato social, Estado, dominio.

\section{ABSTRACT}

The aim of the following article is to explain Hegel's logic and legal philosophy. My purpose is, in one hand, to show the logic and structural unity of Hegel's philosophy, and in the other hand, to search his relations with modern philosophy, especially with Kant's work.

Keywords: being, rationality, unambiguous, freedom, subjectivity, dialectic, abstraction, absolute spirit, civil rights, social contract, State, control. 


\section{INTRODUCCIÓN}

El presente trabajo pretende explorar la filosofía del derecho de Hegel desde un planteamiento estructural. Esta aproximación nos permitirá realizar un acercamiento plenamente filosófico que discuta la lógica del discurso hegeliano, lejos de un análisis descriptivo orientado a subrayar determinados avatares históricos o singulares conexiones sintácticas o etimológicas ${ }^{1}$. Nuestra propuesta, sin embargo, no es ajena al tratamiento actual de la filosofia de Hegel por parte de la doctrina. $\mathrm{Y}$ es que el pensamiento hegeliano, y más en concreto, su filosofía del derecho, ha cobrado una renovada actualidad en los debates teóricos contemporáneo. En buena medida esta rehabilitación se debe a la crisis del marxismo, la cual ha provocado que el pensamiento político contemporáneo recupere los interrogantes y soluciones que caracterizaron la lucha intelectual propia del liberalismo clásico, rejuveneciendo los principales debates teóricos que jalonaron el devenir del siglo XVIII y los primeros años del XIX. En efecto, la cuestión del individuo y su relación con el estado expresan hoy la misma necesidad que hace dos siglos de ser pensados, justificados y reconciliados. Y precisamente, todas estas cuestiones, comprendidas y desnudadas en sus contradicciones internas, fueron respondidas en la filosofía jurídica hegeliana, la cual, tuvo como fin, precisamente, superar el contractualismo moderno. Insertos en este horizonte teórico, nuestro trabajo comenzará sacando a la luz la urdimbre lógica del proyecto filosófico hegeliano y su crítica al entendimiento kantiano, para pasar después a investigar su planteamiento jurídico/político. Para ello, abordaremos La Enciclopedia de las Ciencias Filosóficas $^{2}$ y La Introducción a la Historia de la Filosofia ${ }^{3}$ para la primera parte, y su obra Principios de la Filosofía del Derecho o Derecho Natural y Ciencia Política ${ }^{4}$ para la segunda.

\section{LA LÓGICA IN-FINITA}

La cuestión que se debatirá en las siguientes líneas es si la lógica que articula el pensamiento hegeliano soluciona adecuadamente el objetivo teórico que

1 Esta decisión metodológica no niega, como es obvio, el valor que pueden tener dichas investigaciones, dada la repercusión y la influencia de las ideas hegelianas en autores posteriores, así como la complejidad y originalidad del entramado conceptual y sintáctico que propone.

2 Georg Wilhem Friedrich Hegel, Enciclopedia de las ciencias filosóficas (Madrid: Alianza, 1997).

3 Georg Wilhem Friedrich Hegel, Introducción a la historia de la filosofía (Buenos Aires: Aguilar 1977).

4 Georg Wilhem Friedrich Hegel, Principios de la filosofia del derecho o derecho natural y ciencia política (Barcelona: Edhasa 2005). 
ella misma se arroga, a saber, resolver las aporías que enturbian la modernidad filosófica. Hegel pretende superar el idealismo trascendental kantiano resolviendo sus fracturas e inconsistencias. Dichas fisuras, según la lectura hegeliana, se deben no tanto a errores accidentales o aplicativos sino al propio uso de la razón que Kant emplea. En concreto, Hegel se encuentra persuadido de que las contradicciones en las que ha caído el criticismo trascendental son el resultado de un determinado mecanismo o instrumento racional: el entendimiento. Así pues, la principal crítica que Hegel lanza contra Kant consiste en afirmar que la propuesta filosófica del pensador de Königsberg es el producto de una lógica inadecuada: el entendimiento abstracto ${ }^{5}$. Esta lógica plantea una comprensión basada en el análisis, un análisis que observa la cosa desde fuera, y que solo entiende su objeto de estudio cuando lo distingue y lo separa formalmente a través de sus propias categorías. El entendimiento, piensa Hegel, divide su objeto mediante criterios ajenos a la realidad analizada ${ }^{6}$. Esto provoca que no sea posible alcanzar una unidad epistémica coherente, pues el saber y la cosa conocida son absolutamente extraños.

A la crítica anterior hay que añadir que, para Hegel, la lógica del criticismo tampoco puede dar unidad interna a lo trabado artificialmente por su orden categorial. El entendimiento, divide su objeto en distintos elementos formales que, necesariamente, exigen una unidad última que los concilie, una síntesis que contenga lo previamente diferenciado ${ }^{7}$. Pero esta relación o unidad última, pensada desde la abstracción, no deja de afirmarse como una parte más, como una forma más, y todo porque, "El pensamiento en cuanto entendimiento se queda parado en la determinidad fija y en la distintividad de ella frente a otra"8. La unidad que presuntamente contiene las diferencias, aquello que busca presentarse como lo común, como lo no particular, tal y como es pensado por el entendimiento abstracto, no puede ser sino una parte finita más 9 "La falta de todos los sistemas consiste en que la razón pensante se esfuerza por concebir lo infinito; empero,

5 Como es bien sabido, Kant había distinguido entre las operaciones del sujeto trascendental a nivel teórico entre la sensibilidad, el entendimiento y la razón. Por su parte, Hegel se encuentra persuadido de que el trabajo filosófico que permite semejante acercamiento, se encuentra, a su vez, más cerca del entendimiento científico (portador del orden categorial), que de la unidad última o filosófica que permite efectuar las ideas de la razón y su tránsito al plano moral.

6 En esta crítica Hegel asume todos los cuestionamientos acerca de la cosa en sí vertidos por Jacobi, Reinhold, Maimon y Fichte entre otros y cuestionará que el saber pueda tener una naturaleza completamente diversa a su objeto

7 Ciertamente, este modo de operar analítico que trabaja elaborando distinciones formales que Hegel encuentra en Kant, estaba ya en Descartes, y éste, a su vez, lo recibe de la tradición escolástica medieval en la que recibe su educación.

8 Hegel, Enciclopedia de las ciencias filosóficas, 183.

9 A esta falsa infinitud, como se verá unas líneas más adelante, la denomina Hegel "infinito malo". 
solo puede emplear categorias finitas, y asi lo infinito se hace finito" ${ }^{\text {.10 }}$. La unidad (la síntesis trascendental) característica del planteamiento kantiano ${ }^{11}$, constituye, para Hegel, un vínculo formal y abstracto, una pretendida universalidad o infinitud que no llega a conciliar las diferencias que está llamada a reunir, pues, ella misma instala una última diferencia que perpetúa la fractura "Pero el entendimiento abstracto no puede concebir esto, ya que se queda en las diferencias, solo puede concebir abstracciones, no lo concreto, ni el concepto" 12 . Así pues, la unidad sintética no es sino una última formalidad, una infinitud-finita "Esta infinitud es la mala infinitud o infinitud negativa, por cuanto no es nada más que la negación de lo finito que no obstante vuelve siempre a resurgir por no haber sido también efectivamente superado"13. Esta mala infinitud no es sino otra particularidad que, sin embargo, pretende englobar las anteriores, pero cuya posición, paradójicamente, no hace sino establecer otro límite, otra finitud. Las síntesis trascendentales kantianas no son sino una última abstracción formal que, aun cuando se arrogan el papel de relación, de forma no particular, al quedar hipostatizadas por el pensamiento abstracto, más que reunir, ahondan en la separación que están llamadas a resolver.

Frente a la lógica de la fragmentación propia del entendimiento, la cual, como acabamos de ver, no solo es completamente ajena a la realidad que analiza, sino que además se muestra incapaz de encontrar una unidad última que resuelva sus contradicciones, Hegel apela a una unidad o relación dialéctica o especulativa, que, por un lado, surja del propio objeto que se investiga, y que, por otro, supere las grietas formales propias de lo finito sin derivar o plantear una entidad finita adicional. Para ello, la lógica especulativa debe comenzar su movimiento desde la finitud misma y asimilarla en su movimiento integrador. Hegel defiende que cada uno de los fragmentos finitos que presuntamente se oponen no son sino formas mediadas que encuentran su razón de ser en la totalidad. Así pues, para Hegel, la negación que sufre la finitud implica, a su vez, la superación de su propia unilateralidad abstracta. Lo in-finito es la misma finitud en tanto que sale de sí, se niega en su ser mostrenco, y se relaciona con lo otro de sí trascendiendo su particularidad y su condición ensimismada y unilateral. La negación de la negación característica de la dialéctica hegeliana no representa una tercera entidad finita, sino el desenvolvimiento de la propia finitud, un movimiento mediador que asume y contiene toda contradicción. Lo in-finito es la finitud misma en

10 Hegel, Introducción a la historia de la filosofia, 34.

11 Las dificultades propias de las síntesis trascendentales kantianas han sido objeto de mi trabajo de tesis doctoral: "Una crítica de las críticas. Análisis estructural de la filosofía teórica, práctica y jurídica kantiana", Juan Manuel Espinosa (Tesis doctoral, UNED, 2013).

12 Hegel, Introducción a la historia de la filosofia, 70.

13 Hegel, Enciclopedia de las ciencias filosóficas, 197. 
su desarrollo. La lógica es la verdad del ser en su despliegue. En definitiva, para Hegel, el entendimiento solo observa la parte, lo inmediato, mientras que la lógica especulativa recorre la contradicción y encuentra en la mediación la verdad de lo inmediato "Nosotros no encontramos contradictorio ni puede perturbarnos que el olor de las flores sea otra cosa que el color de las mismas, que el olor y el color se opongan uno a otro, y que, sin embargo, estén simplemente reunidos en un conjunto (...). El entendimiento, por el contrario, dice: la materia es continua o corpuscular, atomística; enfrenta de manera constante ambas determinaciones, una con otra (...). Pero lo verdadero es la unidad de los opuestos (...). Así son opuestas las diferencias en unidad"14.

La lógica hegeliana supera así todas las contradicciones características del entendimiento, resolviendo también la distancia entre el objeto y el sujeto que lastraba al idealismo trascendental. La razón, la Idea, ha de ser la cosa misma en su universalidad, en su desarrollo, y no, como afirmaba Kant, una categoría humana con la que ordenar un mundo nouménico extraño al pensamiento "En vez de ocuparnos de tales inútiles representaciones y maneras de hablar acerca del conocimiento como un instrumento para poseedores de lo absoluto o como un medio a través del cual contemplamos la verdad, etc. -relaciones a las que evidentemente conducen todas estas representaciones de un conocimiento separado del absoluto, y de un absoluto separado del conocimiento- (...); en vez de torturarnos en dar respuesta a todo esto, podríamos rechazar esas representaciones como contingentes y arbitrarias y considerar incluso como un fraude al empleo, con ello relacionado, como lo absoluto, el conocimiento, lo objetivo y lo subjetivo, y otras innumerables, cuyo significado se presupone como generalmente conocido" $"$.

La lógica especulativa, demuestra como la Idea no es externa a su objeto, pues si lo fuera, el conocimiento mismo estaría separado irremediablemente de la realidad a la que se refiere, formando ambas dos partes abstractas y completamente ajenas (fenómeno versus noúmeno; verdad versus realidad), e impidiendo su unidad "Se supone conocido a partir de la lógica el método según el cual en la ciencia el concepto se desarrolla desde sí mismo y progresa y produce sus determinaciones de un modo inmanente. El desarrollo no se produce, pues, por la afirmación de que hay distintas relaciones y por la aplicación de lo universal a una materia tomada de otra parte (...). Considerar algo racionalmente no quiere decir acercar la razón al objeto desde fuera y elaborarlo por medio de ella, sino que el objeto es por sí mismo racional; aquí está el espíritu en su

14 Hegel, Introducción a la historia de la filosofia, 67.

15 Georg Wilhem Friedrich Hegel, Fenomenología del espíritu (México, D.F.: Fondo de Cultura Económica, 1966) 52. 
libertad, la más alta cumbre de la razón autoconsciente que se da en la realidad $y$ se produce como mundo existente" ${ }^{\text {"16 }}$. Así pues, la idea opera internamente, trabaja constituyendo al propio objeto en su desenvolvimiento y no aplicándose al mismo desde fuera "El pensamiento, en cuanto subjetivo, contempla este desarrollo de la idea como la actividad propia de su razón, sin agregar nada por su parte. Considerar algo racionalmente no quiere decir acercar la razón al objeto desde fuera y elaborarlo por medio de ella, sino que el objeto es en sí mismo racional" 17 .

Por eso advierte Hegel que la razón, lo absoluto ${ }^{18}$, el espíritu, lo lógico (lo universal, lo in-finito), es ya la cosa particular, o, lo que es lo mismo, que el sujeto es ya la substancia, que la Idea es ya el ser; ser que necesita abrirse y concretarse, desarrollarse superando las contradicciones o finitudes que le envuelven con el fin de reconocerse, con el objetivo de hacerse plenamente racional, de devenir universal. La finitud es inquietud, particularidad que se despliega reconociéndose en sus contornos, en sus límites. Lo inmediato es abstracción que se hace transparente para sí misma deviniendo autoconsciente; el ser necesita desarrollarse para re-encontrarse como Idea. Así pues, el ser y el pensar, lo real y lo racional, no pueden hallarse separados, tal y como afirmará Hegel en una de sus afirmaciones más reconocibles "Lo que es racional es real, y lo que es real es racional" 19 .

Ahora bien, verdaderamente ¿son el entendimiento kantiano y la razón dialéctica hegeliana dos usos de la razón tan dispares? ¿es la lógica del entendimiento una intelección formal de lo abstracto e inmediato, de lo separado y finito, mientras que la comprensión especulativa constituye una lógica de la relación, de la unidad, de la verdad?

La hipótesis que mantengo en este trabajo es que no. Mi tesis es que la lógica especulativa que Hegel defiende no deja de ser una nueva versión de la racionalidad formalizadora kantiana, con lo que adolece de las mismas debilidades que condujeron al propio Hegel a cuestionar el idealismo trascendental. En concreto, considero que la lógica de Hegel es también una lógica subjetiva, una lógica que se agota en la subjetividad, una lógica que, si bien trasciende la finitud kantiana, no deja de estar vestida por su mismo ropaje: unilateralidad y abstracción. De este modo, y como intentaré mostrar en las líneas que siguen, al

16 Hegel, Fenomenología del espíritu, 109.

17 Hegel, Principios de la filosofía del derecho, 109.

18 Esta búsqueda de lo absoluto, de lo infinito no solo caracterizó la especulación hegeliana, sino que se extenderá a todo el idealismo alemán y también al romanticismo, si bien, al menos en este último, no se pretenderá alcanzar la unidad desde la razón (sea o no dialéctica) sino desde el sentimiento.

19 Hegel, Principios de la filosofía del derecho, 59. 
vincular la única razón posible con la acción libre de un sujeto, Hegel acabará por reducir dicha racionalidad a un ejercicio meramente instrumental. Y del mismo modo que Hegel criticaba, no ya la falsedad, pero si la unilateralidad del entendimiento kantiano, podemos nosotros denunciar, desde el espíritu mismo de la filosofía hegeliana, la parcialidad que supone la rebaja de toda lógica al ejercicio volitivo de un sujeto, aun cuando dicha subjetividad sea la propia del espíritu absoluto. Veamos cómo.

Como se acaba de indicar, lo característico de la lógica hegeliana es la identificación de la razón con la libertad del sujeto infinito. Esta decisión provoca que no se pueda aceptar ningún otro plexo de sentido ubicado fuera de la actividad libérrima de dicha subjetividad. Pero si la razón se encuentra encarnada exclusivamente en dicho sujeto, lo finito quedará reducido a un mero producto de su actividad. Lo particular no alberga ningún contenido lógico ni ontológico intrínseco, sino que su ser se reduce a una estofa amorfa sobre la que se impone la única lógica posible, la lógica dialéctica. Fuera del espíritu absoluto no hay posibilidad de encontrar nada que sea por sí, nada que sea libre. La lógica unívoca propia de la dialéctica hegeliana es incapaz de respetar la variedad de lo finito adaptando su desarrollo a la pluralidad del ser. De ahí que podamos afirmar nosotros que la unidad especulativa hegeliana no deja de ser otra "mala infinitud", otra lógica reducida a las formas propias del sujeto, un sujeto, eso sí, más sublime, más universal que el propuesto por el criticismo kantiano, una subjetividad troquelada de divinidad e historicidad, pero, en cualquier caso, reducción del ser a las formas subjetivas con las que opera la conciencia. El ser, la finitud, pierde así su condición substancial. La substancia se convierte en sujeto. Solo el sujeto y su voluntad, solo el poder del espíritu, tiene la virtualidad de promover su lógica. Lo inmediato, lo abstracto, lo finito, queda necesariamente sometido al dominio de la libertad absoluta, al poder de la voluntad divina. En un sentido análogo, Hegel, refiriéndose a la diferencia jurídica entre la voluntad del sujeto finito y las cosas, afirma que "Todas las cosas pueden derivar propiedad del hombre porque éste es voluntad libre y como tal en y por sí, mientras que lo que está frente a él no posee esta propiedad. Todos tienen el derecho de llevar su voluntad a la cosa o la cosa a la voluntad, es decir, en otras palabras, eliminar la cosa y convertirla en algo suyo (...). Por eso apropiarse quiere decir fundamentalmente manifestar ante las cosas la grandeza de mi voluntad y mostrar que éstas no son en sí, no tienen un fin propio" ${ }^{20}$. Ninguna cosa, ninguna finitud, ningún ser natural, tiene un fin o una lógica propia, sino que su 
existencia queda reducida a materialidad ciega y vacía de sentido, a masa amorfa que solo sirve como medio para el ejercicio de la libertad.

En cualquier caso, considero que la crítica de Hegel a Kant tiene, sin duda, su razón de ser. El idealismo trascendental que Kant plantea, es, ciertamente, un instrumento que aísla y tiñe lo real en función de sus propios intereses, que analiza fragmentado formalmente su objeto de estudio en partes ordenadas según su propio orden categorial, distinciones unívocas que, a la postre, no son susceptibles de ser reconciliadas adecuadamente "En todo sistema dualístico, y muy particularmente en el kantiano, su defecto fundamental se da a conocer por la inconsecuencia de unir lo que en un momento anterior se ha declarado autosuficiente $y$, por tanto, imposible de unir" ${ }^{21}$. Ahora bien, el planteamiento hegeliano, a la postre, no hace sino reproducir esta misma lógica formal, una razón entificadora y autopoyética. Y lo hace, eso sí, esbozando una unidad originaria que contenga lo que en Kant se encontraba separado desde el inicio (ser/lógica, razón teórica/razón práctica, sujeto/objeto, fenómeno/noúmeno, necesidad causal fenoménica/libertad nouménica, deber/felicidad, individuo/ comunidad política, etc.). De este modo, más que resolver la dificultad lógica que constriñe el pensamiento kantiano, más que abrir la lógica trascendental a la diferencia, a la variedad de lo finito, Hegel engulle la totalidad de lo real por medio de un sujeto infinito, de un ego absoluto, de un espíritu divino que subyace a toda diferencia, a toda inmediatez.

El error o la unilateralidad más evidente de esta respuesta, insisto, es que dicha solución acaba uniformando y reduciendo el ser y el conocer a una sola expresión unívoca: el espíritu absoluto. Y al hacerlo, la maniobra idealista acaba reduciendo lo finito a un accidente cuyo único fin consiste en servir de recipiente para la realización del espíritu absoluto. La dialéctica propuesta por Hegel no es sensible a la pluralidad del ser, a la multiplicidad del universo (y con ello, a la pluralidad de los discursos que se acercan a esa diversidad de objetos). Aún cuando Hegel pretenda respetar la singularidad de lo real afirmando la inmanencia del movimiento del espíritu, considero que al hacer de la finitud un momento del absoluto, y al ser éste un desarrollo o movimiento unívoco, lo particular acaba reduciéndose a un simple eslabón en la carrera de Dios hacia sí mismo, a un momento gobernado por la única libertad del absoluto "Esto es el concepto de desarrollo, un concepto enteramente universal. Esto es la vitalidad, el movimiento en general. La vida de Dios en sí misma, la universalidad en la

21 Hegel, Enciclopedia de las ciencias filosóficas, 162. 
naturaleza y en el espíritu, es la evolución de todo lo viviente, de lo más bajo como de lo más alto"22.

La unidad estructural entre el criticismo trascendental y el idealismo especulativo es evidente. Hegel recoge el sujeto trascendental kantiano (que engloba en su universalidad al sujeto epistémico, moral y político, pero que, en cualquier caso, no deja de representar la conciencia y la razón humana, y por tanto, solo puede expresar un pensamiento finito), y, manteniendo la misma lógica unívoca, eleva al sujeto finito a la categoría de espíritu del mundo. Hegel ontologiza y absolutiza la conciencia finita kantiana, convirtiéndola en un sujeto in-finito, en lo absoluto, en Dios, en el sujeto-substancia (idea-ser) universal que ha de contener todas las diferencias, todas las contradicciones. El espíritu, el pensar, la idea, ya no es lo propio y exclusivo de la condición humana o de cualquier ente racional finito, sino que el espíritu constituye la condición de posibilidad propia del universo, la mediación que recorre y contiene todas las finitudes. El pensamiento, la razón, la idea, es el movimiento del todo, el camino de Dios en el mundo. La epistemología, la ética y la estética formal kantianas se transforman en una onto-teología dialéctica ${ }^{23}$. El sujeto es la substancia, la Idea es Dios, la forma abstracta es un momento del ser, el bien y la verdad trascendental son el pensamiento mismo que el universo tiene sobre sí, el espíritu del mundo en su despliegue, "Decimos pensamiento y nos representamos algo subjetivo; cuando reflexionamos, tenemos pensamientos sobre cosas; los pensamientos no son las cosas mismas, sino formulados sobre las cosas. Pero estas no son verdaderos pensamientos; son meramente subjetivas y, por consiguiente, casuales. Pero, al ser el pensamiento lo universal, es así objetivo"24.

Así pues, la conciencia finita kantiana deviene el espíritu divino hegeliano. Y como el sujeto trascendental kantiano se caracteriza por su libertad (ideal que, no en vano, constituye la seña de identidad de la modernidad ilustrada), Hegel atribuirá esta misma característica al espíritu del mundo ${ }^{25}$. Lo in-finito, lo

22 Hegel, Introducción a la historia de la filosofia, 61.

23 Ciertamente, Kant ya había dado pasos muy importantes hacia esta conclusión en su crítica práctica. Allí, no solo defendía la filosofía moral como el conocimiento más verdadero y valioso para el ser humano, sino que además hacía recaer todos los fundamentos y justificaciones del imperativo categórico, esto es, de la ley moral formal, sobre la fe racional en la existencia de Dios. También la ética kantiana acababa así su planteamiento presuntamente ilustrado y moderno, apelando a la divinidad como única entidad garante de la libertad y de la justicia humana.

24 Hegel, Introducción a la historia de la filosofia, 32.

25 Por otro lado, Hegel piensa que la libertad y la racionalidad se implican mutuamente. Ser racional, ser capaz de pensar, es la condición de posibilidad de la libertad misma. De hecho, para Hegel, la única diferencia entre ambas es que la razón es lo propio de lo teórico, y la libertad de lo práctico: "Pero no hay que representarse que el hombre por una parte piensa y por otra quiere (...). La diferencia entre pensamiento y voluntad es la que existe entre el comportamiento teórico y el práctico, pero no son 
absoluto, se define por su absoluta autonomía, una libertad plena que se irá desplegando en el tiempo y en la historia. En este desarrollo del absoluto, el hombre, su cultura y su historia ocupan un momento central, dado que se encarna en ellos el más alto grado de libertad y autoconciencia de sí de esa naturaleza espiritual. Pero, en cualquier caso, la libertad es lo propio de cada ser humano particular, sino que constituye la esencia del universo, la vida de Dios llegando a la plena conciencia de sí "Es la eterna vida de Dios encontrarse a sí misma, devenir por sí, fusionarse consigo misma (...) Precisamente este movimiento es lo que se llama libertad" 26 .

Pasaré a continuación a observar esta in-finitud que se mueve hacia su plena libertad y racionalidad en ese momento culminante que acabamos de señalar, en el mundo humano y en su cultura, en el mundo de las costumbres, en el derecho. Aquí, observaremos como el desarrollo lógico del espíritu transita desde la libertad individual que caracteriza al derecho abstracto, hasta la idea del Estado como actualización de esa misma libertad individual en la eticidad. Estudiaremos como el individuo y la comunidad política (y su expresión jurídica: la ley), representan ambos el desarrollo o el despliegue del espíritu absoluto, y no el conflicto y la separación entre diversas partes o entidades que luego habría que reunir artificialmente. Este desarrollo estatal constituye un momento central en ese despliegue del espíritu del mundo que venimos estudiando, y no una mera consecución azarosa y contingente en la historia de la civilización humana.

\section{LA LIBERTAD IN-FINITA}

En el análisis jurídico y político contenido en su obra publicada en 1821, Principios de la Filosofía del Derecho o Derecho Natural y Ciencia Política ${ }^{27}$, Hegel volverá a tener como objetivo teórico prioritario eliminar las contradicciones lógicas que hieren el conjunto de las filosofías políticas modernas, y en concreto las propuestas de Rousseau y Kant. En estas filosofías la lógica del entendimiento abstracto provoca que la libertad individual no pueda conciliarse adecuadamente conformando una verdadera comunidad política, la cual, por otro lado, constituye el único espacio en el que puede ejercerse con "propiedad"

dos facultades, sino que la voluntad es un modo particular de pensamiento: el pensamiento en tanto que se traduce en la existencia, en cuanto impulso de darse la existencia". Hegel, Principios de la filosofía del derecho, 79.

26 Hegel, Introducción a la historia de la filosofia, 61.

27 Hegel, Principios de la filosofía del derecho. 
esa misma libertad original ${ }^{28}$. Otra vez, la visión unilateral (no falsa, pero si abstracta y por tanto, parcial e incompleta) propia del entendimiento entra en contradicciones insalvables desde el momento en que separa, distingue y substancializa la voluntad particular.

Cierto es que, para Hegel, la modernidad filosófica hace lo correcto al considerar la libertad como el fundamento de toda legitimidad política. Sin embargo, al utilizar una lógica que es incapaz de ir más allá de lo finito, de lo individual, los filósofos modernos solo pueden concebir la unidad o totalidad comunitaria como una finitud más. La abstracción o entificación característica del entendimiento, en su aplicación al ámbito jurídico y político, vuelve a plantear límites o finitudes que luego es incapaz de resolver, impidiendo reunir coherentemente la serie de individuos que componen la comunidad política "En la investigación de este concepto, Rousseau ha tenido el mérito de establecer como principio del Estado un principio que no solo según su forma (como por ejemplo el instinto de sociabilidad, la autoridad divina), sino también según su contenido, es pensamiento y, en realidad, el pensar mismo: la voluntad. Pero su defecto consiste en haber aprendido la voluntad solo en la forma determinada de la voluntad individual (...),29.

Los teóricos del moderno derecho natural, defiende Hegel, solo reconocen la existencia de la voluntad finita, lo que les conduce a entender lo político como una lucha irreconciliable entre intereses abstractos y contrapuestos, definiendo la voluntad general como una mera suma o agregado de voluntades singulares. Esta respuesta individualista, abstracta y unilateral acaba convirtiendo toda relación comunitaria en un campo de batalla por la consecución de un interés particular, transformando las relaciones políticas en el reino de la necesidad material, del egoísmo hobbesiano "Muchos de los modernos doctrinarios del derecho público no han salido de esta comprensión del Estado. En la sociedad civil cada uno es fin para sí mismo y todos los demás no son nada para él (...) los otros son, por lo tanto medios para el fin de un individuo particular" ${ }^{\prime 3}$.

Estas últimas palabras de Hegel nos conducen a otro aspecto fundamental de su crítica a la filosofía del derecho propia del liberalismo moderno. Y es que este planteamiento cae en el error de confundir la sociedad civil con el Estado.

28 Esta dialéctica fue definida por Kant como la insociable sociabilidad intrínseca al ser humano "Entiendo aqui por antagonismo la insociable sociabilidad de los hombres, esto es, el que su inclinación a vivir en sociedad sea inseparable de una hostilidad que amenaza constantemente con disolver esa sociedad". Inmanuel Kant, Ideas para una historia universal en clave cosmopolita (1784). Ensayos sobre la paz, el progreso y el ideal cosmopolita (Madrid: Ediciones Cátedra, 2005) 37.

29 Hegel, Principios de la filosofía del derecho, 363.

30 Hegel, Principios de la filosofía del derecho, 305. 
Los doctrinarios del derecho moderno confunden el espacio de la necesidad en la que el individuo lucha por satisfacer sus intereses particulares con las institu-

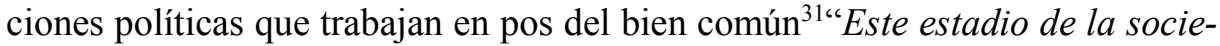
dad civil ha sido frecuentemente tomado por el Estado mismo. Pero el estado solo es el tercero, es la eticidad misma y el espiritu, en el que tiene lugar la unión de la independencia de la individualidad y la sustancialidad universal"32. Esta confusión provoca que los defensores del derecho natural conciban la comunidad política no como el orden que realiza el bien común, sino como el cauce o instrumento político que institucionaliza el conflicto, el cual, sin embargo, no puede superarse, dado que el ser humano no puede buscar otro fin que aquel que materializa su propio interés particular (su propia necesidad de realizar sus fines como propietario). Si solo se acepta la existencia de derechos de propiedad subjetivos y abstractos, no puede haber otro bien que aquel que se encarna en el interés particular. De ahí que la comunidad política no represente una verdadera unidad orgánica y universal. Al considerar el espacio político como un simple agregado de subjetividades, de propietarios independientes, no hay posibilidad de restaurar la unidad, de dejar sitio a la relación, a lo común, a lo universal.

Todas estas convicciones provocan, finalmente, que Hegel denuncie como quimérica la idea del Contrato Social como la expresión política que garantiza los derechos de libertad y de propiedad, idea que se había convertido en la propuesta paradigmática del pensamiento jurídico moderno. En efecto, Hegel no puede aceptar la idea de un supuesto acuerdo que sirva como instrumento a través del cual se sumen las voluntades singulares en aras de un provecho egoísta pero recíproco. Este ideal sintetizador es, más bien, una ilusión abstracta y formal sin concreción real, que solo puede conducir al infinito malo, esto es, a la suma de libertades individuales o partes aisladas, y finalmente, a la dictadura de una de ellas, sin llegar a una conciliación o unidad posible, sin alcanzar la idea universal, sin definir el bien común. El contractualismo clásico constituye pues, según la interpretación hegeliana, la visión formal y unilateral propia del entendimiento abstracto, la cual, además de entificar la voluntad universal, olvida la condición histórica u objetiva de las comunidades políticas y afirma su aparición o constitución a través de un ideal externo y separado de toda facticidad social,

31 Esta confusión entre la necesidad y la justicia será lo que, últimamente, Habermas denomine la colonización del mundo de la vida por parte de la razón estratégica propia del mercado capitalista.

32 Hegel, Principios de la filosofía del derecho, 114. 
apartado de toda substancia histórica, afirmando un origen absolutamente ideal y a priori $^{33}$.

Frente a este ideal abstracto y ahistórico, Hegel comprenderá su propia propuesta filosófica como la culminación de esa modernidad de la que se siente heredero, superación que otra vez se sostiene en el uso de la lógica dialéctica. De hecho, Hegel buscará superar las fracturas de la filosofía política moderna conciliando su principio fundamental, la libertad individual ("el principio del mundo moderno es la libertad de la subjetividad" "34), con el planteamiento teórico propio del mundo antiguo ${ }^{35}$, el cual considera la comunidad política como un todo orgánico ("El estado es un organismo, es decir, el desarrollo de la idea en sus diferencias" "36). El filósofo idealista intentará así articular una lógica que permita reconocer el valor de los derechos individuales reivindicados por la modernidad (los cuales tienen su expresión paradigmática en el derecho de propiedad: "Puesto que por medio de la propiedad le doy existencia a mi voluntad"37), sin renunciar a la idea de una comunidad política entendida como totalidad. Y lo hará, como digo, sin rechazar el principio moderno fundamental, la libertad, pero sin caer en una visión parcial, abstracta y unilateral. El Estado no puede ser el molde donde se resuelva mecánica y formalmente el conflicto entre subjetividades individuales, ni el marco jurídico a través del cual una de las voluntades particulares se dilate e imponga su querer unilateral, porque si así fuera, el bien común, el interés del Estado, representaría tan solo una conciencia particular, un provecho privado, una parte, un arbitrio, un querer sensible, y no el todo, no lo universal, no la razón, no la Idea. El Estado tiene que representar la institución u organización donde se exprese la libertad universal, la Idea, lo in-finito, "Es

33 "Se presenta de inmediato otra pregunta ¿quién debe hacer la constitución? Esta pregunta parece clara, pero muestra sin embargo, a una consideración más detenida, que carece de sentido. Presupone, en efecto, que no existe ya ninguna constitución y que solo hay una multitud atomística de individuos reunidos. Cómo una multitud de este tipo puede llegar a una constitución, si por sí misma o por otros, si por la bondad, el pensamiento o la fuerza, habría que dejarlo en sus manos, pues el concepto no tiene nada que ver con una multitud atomística (...). Por otra parte, es esencial señalar que la constitución, aunque haya surgido en el tiempo, no debe ser considerada como algo hecho; es por el contrario lo existente en y por sí, y por lo tanto hay que considerarlo por encima de la esfera de lo que se hace, como lo divino y persistente" Hegel, Principios de la filosofía del derecho, 417.

34 Hegel, Principios de la filosofía del derecho, 417.

35 Aristóteles en su Política asegura que "Asi pues, es evidente que la ciudad es por naturaleza y es anterior al individuo; porque si cada uno por separado no se basta a sí mismo, se encontrará de manera semejante a las demás partes en relación con el todo. Y el que no puede vivir en comunidad,o no necesita nada por su propia suficiencia, no es miembro de la ciudad, sino una bestia o un dios" Aristóteles, Política, (Madrid: Gredos, 1982), 32.

36 Hegel, Principios de la filosofía del derecho, 389.

37 Hegel, Principios de la filosofía del derecho, 131. 
el camino de Dios en el mundo que constituye el Estado; su fundamento es la fuerza de la razón que se realiza como voluntad" ${ }^{38}$.

La propuesta especulativa hegeliana busca, pues, superar esta lógica de la diferencia, esta imposible política del individuo, esta insociable sociabilidad en la que se atasca el entendimiento abstracto, eso sí, manteniendo la libertad de la subjetividad como idea rectora. La dialéctica vuelve a tener como fin conciliar la parte y el todo sin plantear lo común como una última entidad parcial. Así, solo si el individuo y el Estado, la voluntad individual y la ley universal, comparten cierta mismidad, la lucha de intereses irreconciliables propia de la sociedad civil podrá ser superada, asumida y perfeccionada en el Estado. Llevado por esta convicción, Hegel armoniza al sujeto libre y la forma estatal asegurando que ambos son momentos del camino del espíritu en el mundo. No hay una otredad radical, ni metafísica ni política, entre el individuo y la comunidad política sino que ambos son etapas o momentos en la actualización de la razón y de la libertad en la historia. El espíritu objetivo, el Estado, no es otra cosa que la plasmación de la razón y de la libertad universal, cualidades que, en su momento abstracto e inconsciente, caracterizan también al individuo finito, al espíritu subjetivo. Así pues, dicha razón libérrima, en un primer momento, se encuentra agazapada, implícita en la conciencia moral subjetiva, y solo en el Estado como entidad universal, como totalidad objetivada, esa misma libertad alcanza su concreción plena, su absoluta perfección y conciencia de sí, su ser en sí y para sí, su eticidad.

De este modo, el individuo y el Estado representan momentos o etapas del mismo movimiento del espíritu, y no partes o finitudes separadas de manera abstracta y luego artificialmente reunidas a través de un contrato. Hegel partirá de la libertad individual como principio moderno irrenunciable para concluir en la comunidad o unidad estatal como hecho histórico objetivo donde se alcanza la plena libertad tanto individual como universal ${ }^{39}$, "La esencia del nuevo Estado es que lo universal está unido con la completa libertad de la particularidad y con la prosperidad de los individuos...." ${ }^{40}$. El ser en sí, la libertad individual o abstracta como instancia constitutiva de todo derecho, de toda justicia, se volcará sobre sí alcanzando su plena conciencia en la moralidad (en la interioridad subjetiva en la que se quedaba la posición trascendental kantiana), para,

38 Hegel, Principios de la filosofía del derecho, 375.

39 Hegel atribuye así un valor universal, necesario y atemporal a las ideas de libertad y de propiedad surgidas en la sociedad burguesa.

40 Hegel, Principios de la filosofía del derecho, 380. 
finalmente, exteriorizarse y objetivarse históricamente en la eticidad ${ }^{41}$ en forma de instituciones familiares, sociales, y, finalmente, también políticas, alcanzando de este modo, a través del Estado, la plena universalidad y autoconciencia, y por tanto, la realización absoluta de esa misma libertad original: "El derecho es algo sagrado sólo porque es la existencia del concepto absoluto, de la libertad autoconsciente (...). La moralidad, la eticidad, el interés del Estado, constituyen cada uno un derecho peculiar, porque cada una de estas figuras es una determinación y existencia de la libertad" ${ }^{\prime 2}$.

La lógica hegeliana consigue así articular una filosofía política donde el Estado no represente un interés particular más, y donde la libertad individual y el poder político no se afirmen como dos entidades absolutamente antagónicas e irreconciliables. Por el contrario, ambas integran momentos necesarios en el desenvolvimiento del espíritu. Hegel lleva a su culminación la idea de justicia presente en las propuestas de Rousseau y de Kant, donde la ley, para ser justa, solo puede prescribir aquello que voluntariamente ha escogido el propio individuo. Las normas jurídicas se presentan así no como la expresión de una autoridad externa y heterónoma, sino como la obligación que el sujeto establece para sí. De este modo se identifican derecho y libertad, ley y voluntad, estado e individuo. Pero a esta idea de libertad y legalidad se le añaden, como venimos constatando, dos importantes matizaciones. Por un lado, el carácter de conciencia divina que se revela para sí misma a través de la actividad intelectual humana, y por otro, la necesaria concreción y perfeccionamiento de esa misma libertad en las instituciones culturales, sociales y políticas como vehículo de ese mismo espíritu universal (idea que le llega a Hegel de Montesquieu y Herder). En este sentido, Hegel asegura que cada estado concreto se encuentra a un distinto nivel de plasmación o actualización del espíritu universal. La libertad y la razón aparecen en el mundo en forma de ideas subjetivas, pero también, en las instituciones humanas que las plasman, que las objetivan. Por eso cada pueblo tiene un espíritu (subjetivo y objetivo) que se encuentra en un momento distinto del desenvolvimiento de la razón universal, y por eso mismo, como advertíamos más arriba, las constituciones no se crean, no aparecen ex nihilo, no se otorgan "Ninguna constitución puede ser creada, por lo tanto, meramente por sujetos. Lo que Napoleón dio a los españoles era más racional que lo que tenían previamente, y sin embargo, lo rechazaron como algo que les era extraño, porque no se habían desarrollado aun hasta ese nivel. Frente a su constitución el pueblo

41 Como es sabido, el derecho abstracto, la moralidad y la eticidad componen las tres partes o capítulos que conforman la obra ético-política fundamental de Hegel, la ya mentada Principios de la Filosofia del Derecho.

42 Hegel, Principios de la filosofía del derecho, 107. 
debe tener el sentimiento de que es su derecho y su situación; si no, puede existir exteriormente, pero no tendrá ningún significado ni valor" ${ }^{\prime 3}$.

Ahora bien, ¿logra Hegel con esta estrategia teórica superar la brecha entre lo particular y lo universal? ¿consigue el filosofo idealista aunar en un todo la subjetividad finita guiada por intereses egoístas y el Estado o la comunidad política constituida por leyes universales?

Mi tesis, análoga a la expresada en el epígrafe anterior, es que no. Considero que Hegel, en pos de la coherencia y la racionalidad sistemática del discurso iusfilosófico moderno, reducirá al individuo a un momento del absoluto; y con esta decisión, el propio Hegel caerá (en contra de sus propias intenciones teóricas), en una abstracción formal en la que se reduce lo real a uno de sus términos. Si el liberalismo clásico había angostado el ámbito político reduciéndolo al individuo y a su voluntad (a su libertad como propietario en el espacio social), negando así cualquier valor a la comunidad misma, Hegel, manteniendo la misma lógica unívoca, trocará la metafísica del individuo por una metafísica del Estado. La lógica dialéctica hegeliana, al identificar la verdadera libertad con la actualización del espíritu absoluto, al convertir en divina e infinita la autonomía e independencia característica del sujeto trascendental kantiano, provocará que el sujeto finito deje, en esencia, de ser un ser por sí, y que su hacer como ciudadano se reduzca a servir de vehículo en el advenimiento del Estado. La vida del individuo se convierte así en un mero instrumento en manos de la totalidad estatal. La libertad humana solo es tal en su contribución a la aparición de las instituciones estatales, y no en su acción o proyección individual "Pero únicamente con el conocimiento de que la idea de la libertad es solo verdadera como Estado se asegura que el espiritu objetivo, el contenido del derecho, no sea nuevamente reducido a algo subjetivo" 44 .

El individuo deja de ser, en lo fundamental, un ser autónomo, un fin en sí mismo, y pasa a convertirse en un instrumento cuyo único sentido y valor se encuentra en contribuir al desarrollo del Estado. Hegel niega la fractura entre el ciudadano y el Estado, entre el individuo y la ley, entre lo particular y lo universal, porque cercena la singularidad característica del ser humano moderno. El sujeto no constituye un ser libre y emancipado de la naturaleza o del poder político, un ser soberano, un ser independiente de toda autoridad, pues su verdadera condición se reduce a mero momento en la concreción de lo absoluto, un accidente en la actualización del espíritu "El espiritu tiene realidad y sus

43 Hegel, Principios de la filosofia del derecho, 418

44 Hegel, Principios de la filosofía del derecho, 142. 
accidentes son los individuos" $" 45$. No hay construcción individual de la identidad personal, pues todo lo humano se encuentra transido de universalidad, de divinidad, de Estado, "Por ser el Estado el espiritu objetivo, el individuo solo tiene objetividad, verdad y ética si forma parte de él" ${ }^{\text {" }}$. El universo en su conjunto, pero también, y con más razón, el universo social y político propio de lo humano, está gobernado por una necesidad férrea. El mundo se encuentra regido por una lógica dialéctica que obliga a cada sujeto individual a entregar su ser y servir de camino en la actualización del Estado. El Estado se encuentra muy por encima del individuo, o más bien, aparece como una entidad infinita de la que el individuo solo representa un mero eslabón. Dicho de otro modo, Hegel, en su pretensión de culminar la modernidad, comprenderá toda relación jurídica y política como una cuestión que atañe, esencialmente, a la libertad de un sujeto, aun cuando en este caso dicha voluntad subjetiva se entenderá no tanto como la expresión de una intencionalidad individual, sino como la manifestación del querer de un ser infinito. Como vemos, la filosofía jurídica hegeliana no abandona el esquema y la lógica de la subjetividad moderna, pero al atribuir a lo infinito la única libertad posible, la finitud humana acabará considerándose como un mero objeto al servicio de la divinidad: "Respecto de la libertad, no debe partirse de la individualidad, de la autoconciencia individual, sino de la esencia de la autoconciencia, pues esta esencia, sea o no sabida por el hombre, se realiza como una fuerza independiente en la que los individuos son solo momentos. Es el camino de Dios en el mundo lo que constituye el Estado; su fundamento es la fuerza de la razón que se realiza como voluntad"47. El estado no es, pues, el lugar donde se persigue el fin o el bien de una comunidad política, sino que las instituciones estatales realizan, únicamente, el querer de una voluntad. El estado hegeliano se reduce a la expresión del dominio de una subjetividad infinita no mediada ni por lo real ni por ninguna otra voluntad. En este sentido, se puede decir que en Hegel desaparece toda relación jurídica tanto objetiva como intersubjetiva. La justicia, lo político, el derecho, la ley, representan el ejercicio de una sola voluntad, la expresión de una lógica que se reduce a las decisiones de un sujeto absoluto, al ejercicio del dominio del espíritu absoluto.

Podemos concluir este epígrafe señalando que la decisión moderna de reducir toda legitimidad a la voluntad de un sujeto, provoca que la racionalidad no pueda ir más allá de la pura lógica instrumental. En efecto, Kant, y con él, el conjunto de la modernidad, al reducir la justicia a la libertad humana, y al caracterizar ésta como una actividad que se realiza preferentemente a través de los

45 Hegel, Principios de la filosofia del derecho, 275.

46 Hegel, Principios de la filosofía del derecho, 371.

47 Hegel, Principios de la filosofia del derecho, 375. 
derechos de propiedad, entenderá la dimensión política del hombre como una esfera que se reduce a la maximización inteligente de esos mismos derechos de apropiación. El ciudadano se reduce a un mero homo oeconomicus. El ámbito político pierde su vocación ética, su lógica de la solidaridad, para comprimirse en una suerte de lógica estratégica e instrumental. La inteligencia política queda así rebajada a una razón meramente economicista, a un cálculo astuto. La racionalidad se reduce a la búsqueda de la maximización de utilidades. El mundo en general, y también los otros sujetos, son meros objetos sometidos a esta lógica eficientista, simples engranajes o mercancías al servicio de la producción capitalista, tal y como denunciará Marx ${ }^{48}$. En cualquier caso, a esta despotenciación de la naturaleza moral de la racionalidad política que convive en todo el pensamiento moderno hay que añadir que Hegel, al atribuir ese ejercicio racional de apropiación no ya al sujeto finito sino al espíritu absoluto, provocará que el control del hombre sobre el hombre se torne en una dominación que se ejerce desde fuerzas sistémicas e impersonales. Serán las estructuras sociales y estatales gobernadas por esta lógica estratégica las que acaben cercenando la autonomía del individuo. La organización política, administrativa y económica devora y somete la dignidad del ser humano convirtiendo al individuo en un mero engranaje subyugado a los fines del sistema. Vemos pues que, tal y como diagnosticaron Adorno y Horkheimer (aún cuando atribuyeran esta perversión al conjunto de la

48 A esta mercantilización u objetivación del ser humano Marx la denominará la fetichización de la mercancía. Y es que, para Marx, el capitalismo reduce al hombre y sus relaciones a un mero trato mercantil: "El salario habitual es, según Smith, el mínimo compatible con la simple humanidad, es decir, con una existencia animal. La demanda de hombres regula necesariamente la producción de hombres, como ocurre con cualquier otra mercancía" Karl Marx, Manuscritos de economía y filosofía (Madrid: Alianza, 2001), 52. Así pues, todas las cualidades y atributos humanos se miden en función del dinero. En cualquier caso, la dialéctica marxista reproduce estructuralmente la misma lógica unívoca hegeliana. Marx materializa el espíritu absoluto hegeliano manteniendo su necesidad y su autarquía. El trabajo del hombre es ahora el protagonista único de la razón sobre el mundo. Marx trueca la actividad espiritual del absoluto hegeliano por el ejercicio productivo del ser humano genérico, pero mantiene la lógica de la subjetividad moderna que Hegel había heredado de Kant. La razón se vuelve a reducir unívocamente a un proceso ciego de instrumentalización que, esta vez, se expresa no ya en los productos intelectuales producidos por el espíritu, sino que lo harán en los procesos económicos de carácter sistémico, los cuales, en cualquier caso, se fundan en el trabajo del hombre, en el ejercicio productivo por medio del cual el ser humano impone su voluntad al mundo y a sí mismo. A esta reformulación materialista de la filosofía moderna hay que añadir que Marx entiende el estado hegeliano como la expresión del estado burgués, y por tanto, como el mecanismo de dominio de una clase sobre otra. El estado no es la institución que realiza el interés universal. La totalidad, la razón, la justicia, solo puede aparecer cuando la eliminación de la propiedad privada acabe con los intereses de clase y el ser humano como ser genérico, como ser universal, viva en un sistema político ya sin conflictos ni oposiciones, en un sistema sin división del trabajo, en una sociedad donde cada hombre sea todo hombre, donde la libertad y la promesa de emancipación se puedan realizar en la tarea productiva de cada individuo como un todo y no a través de las instituciones estatales. 
actividad racional humana y no a las angosturas de la razón moderna ${ }^{49}$ ), la promesa de emancipación que la ilustración blandía, contenía ya su propia contradicción; será su propia lógica la que terminará por reducir todo uso de la razón a un mecanismo de dominio y de control del sistema político y económico sobre el hombre.

\section{IV.CONCLUSIONES}

La conclusión más evidente que podemos extraer del presente estudio es la profunda unidad estructural que atraviesa el conjunto de la filosofía hegeliana. A su vez, esta unidad solo se puede cumplir a través de la idea del Espíritu o pensamiento absoluto. Mediante este ideal, Hegel consigue que cada una de las entidades metafísicas, epistémicas o políticas finitas encuentren su unidad y se afirmen como meros instantes del todo, como momentos del espíritu absoluto en su desarrollo inmanente. La dialéctica, el movimiento especulativo recorre así, unívocamente, el conjunto del pensamiento hegeliano, dado que, para el propio Hegel, dicho movimiento es en sí mismo universal: la verdadera naturaleza del proceso a través del cual el pensamiento de Dios se reconoce a sí mismo. Esta univocidad lógica y metafísica acaba, efectivamente, con las contradicciones que atenazaban al entendimiento kantiano, si bien, como se ha puesto de manifiesto en la presente investigación, desemboca en nuevas dificultades gnoseológicas y filosóficas de difícil solución.

El principal problema teórico que hemos encontrado es la unilateralidad que supone la reducción de toda singularidad al movimiento de la lógica dialéctica. No hay posibilidad de reconocer otro tipo de lógica, otra forma de ser o de pensar distinta al despliegue del pensamiento del absoluto. El mundo en su totalidad, desde lo más abstracto hasta lo más concreto, se conduce por esta lógica dialéctica. Este planteamiento niega así tanto la singularidad y particularidad de los distintos procesos naturales como la autonomía e independencia de las acciones gnoseológicas, morales y políticas humanas.

Esta ubicuidad lógica y metafísica mantiene su fidelidad estructural con la filosofía moderna. Ahora bien, este sujeto, este yo, no será una conciencia finita sino divina. El sujeto/substancia hegeliano desborda la subjetividad trascendental propia de la filosofía kantiana hasta convertirla en una entidad divina muy cercana a la infinitud spinosista. Esta postura nos lleva a mantener (a nosotros, y al propio Hegel), que su filosofía, a pesar de la ontologización que propone,

49 De ahí que solo fueran capaces de liberarse de la camisa de fuerza de la racionalidad científica y filosófica, del trabajo conceptual, a través de la expresión o representación que constituye al arte. 
no abandona los márgenes del pensamiento moderno. En efecto, Hegel hace del ser un sujeto, trocando así la epistemología kantiana por una onto-epistemología teológica. Es cierto que la subjetividad absoluta que Hegel plantea resuelve todas las aporías en las que caía el criticismo kantiano al contener y asumir todas las rupturas que aquél no llegada a reconciliar coherentemente, si bien, dicha maniobra acabará reduciendo, tal y como venimos denunciando, todo ser particular a un mero momento en el camino de la infinitud hacía sí misma. Finalmente, esta solución, adolece del mismo vicio que el propio Hegel criticaba al formalismo kantiano, a saber, el de comprender la cosa desde un análisis externo a la misma realidad analizada.

Por último, en lo que se refiere a su filosofía jurídica, hemos señalado la unidad de pensamiento que mantiene esta disciplina con su propuesta lógica y metafísica. En efecto, en su filosofía del derecho también pretende Hegel unir en una totalidad coherente las distintas libertades particulares y la acción del Estado. Esta solución dialéctica solventa los antagonismos irreconciliables que planteaba el atomismo político moderno, pero al hacerlo, Hegel reduce la libertad o la autonomía del sujeto finito a un instante del espíritu absoluto. El ciudadano moderno se convierte en un momento en el desarrollo y aparición del Estado. La unidad dialéctica entre la libertad individual y el estado se consigue a costa de negar cualquier diferencia, a costa de atribuir al individuo una libertad que no es suya sino de otro, una voluntad que no expresa su singularidad sino el viaje de la razón y de la libertad de Dios sobre el mundo. El individuo es un mero instrumento cuya única utilidad es la producción del estado.

En cualquier caso, esta lógica de la libertad infinita no puede dejar de arrastrar y reproducir la visión moderna de la voluntad como deseo de apropiación. La libertad absoluta hegeliana se realiza también en los derechos de propiedad, en los derechos de posesión y dominio, lo que provoca, finalmente, que la racionalidad inscrita en esa misma voluntad infinita se reconozca solo en su aspecto instrumental, en su acción estratégica.

Así pues, parece que el pensamiento político hegeliano, si bien denuncia muy originalmente las angosturas del moderno derecho natural, no puede desembarazarse de los fundamentos lógicos que lo orientan. En este sentido, considero que no hay posibilidad de criticar la unilateralidad de la concepción liberal de la comunidad política como un simple agregado de subjetividades y acogerse a la idea de unidad estatal propuesta por la filosofía hegeliana sin aceptar también la idea de una libertad y razón absolutas, sin acoger la idea de un sujeto 
absoluto, sin postular la idea de $\operatorname{Dios}^{50}$. Y este planteamiento, finalmente, provoca una notoria sobredimensión del Estado y la rebaja del individuo a un mero engranaje en la aparición del mismo.

\section{REFERENCIAS BIBLIOGRÁFICAS}

Álvarez Gómez, Mariano y Ma del Carmen Paredes Martín, eds. Razón, Libertad y Estado en Hegel. Salamanca: Ediciones Universidad de Salamanca, 2000.

- La controversia de Hegel con Kant. Salamanca: Ediciones Universidad de Salamanca, 2004.

Aristóteles, Política. Introducción, traducción y notas de Manuela García Valdés. Madrid: Editorial Gredos, 1982.

Bastit, Michel. El nacimiento de la ley moderna, traducción de Nora Pereyro, Buenos Aires: Editorial de la Universidad Católica Argentina, 2005.

-. Les Quatre causes del 'etreselon la philosophie premiere d'Aristote, Lovain, Paris- Sterling, Virginia: Peeters, 2002.

Brooks, Thom. Hegel's political philosophy. A systematic reading of the philosophy of right. Edinburgh: Edinburgh University press, 2007.

Contreras Peláez, Francisco J. El tribunal de la razón. El pensamiento jurídico de Kant. Sevilla: Editorial Mad, 2005.

Cuartango, Román G. Una nada que puede serlo todo (reflexividad en la ciencia de la lógica de Hegel). Santander: Editorial Límite, 1999.

-. Hegel, filosofía y modernidad. Barcelona. Editorial Montesinos, 2005.

Deleuze, Gilles. Diferencia y Repetición. Madrid: Ediciones Jucar, 1988.

50 En este sentido afirma el filósofo español Manuel Jiménez Redondo en su introducción a la obra de Jürgen Habermas, Textos y Contextos, como no es posible apropiarse de una parte de la filosofía hegeliana sin asumir con ella el pensamiento del todo. Este hecho, condiciona muy mucho toda la herencia política que recibió la izquierda hegeliana de la que la teoría crítica de la Escuela de Francfurt y la propia posición de Habermas son una de sus últimas manifestaciones. En efecto, Jiménez Redondo afirma así que "Comentando a Hegel y señalando con sorna a la izquierda hegeliana, Heidegger dice en una ocasión que hay quienes piensan poder saquear a Hegel sin llevarse entre los despojos los misterios de la santísima trinidad. Bromas aparte, lo que sí pensó la izquierda hegeliana fue poder saquear a Hegel sin llevarse entre los despojos la metafísica entera de Hegel. Heidegger explica cómo ello no es posible. Naturalmente, sus explicaciones hacen referencia a como el pensamiento de Hegel es un pensamiento del absoluto y, una vez el absoluto entra en danza, el pensamiento del absoluto (genitivo objetivo), es decir, el pensamiento que versa sobre lo absoluto, no puede ser sino pensamiento del absoluto (genitivo subjetivo), es decir, pensamiento que pertenece al absoluto, esto es, pensamiento en que el absoluto consiste. Y entonces, cualquiera que sea el fragmento de Hegel que se tome, expresado además como estará en el lenguaje de los dioses, es decir, en un lenguaje articulado en forma de proposiciones especulativas, resultará que ese fragmento no podrá ser sino una estación del autoengendramiento del absoluto y del retorno a sí de ese absoluto autoengendrado, en que la vida (por tanto trinitaria) del absoluto consiste" Manuel Jiménez Redondo, Introducción a Textos y contextos, Jurgüen Habermas (Barcelona: Ariel, 1996), 13. 
Diaz, Carlos. El sueño hegeliano del estado ético. Salamanca: Editorial San Esteban, 1987.

Duque, Félix. La fuerza de la razón, invitación a la lectura de la Crítica de la Razón Pura de Kant. Madrid: Dykinson, 2002.

- Historia de la filosofia moderna, la era de la crítica. Madrid: Akal, 1998.

Espinosa, Juan Manuel. "Una crítica de las críticas. Análisis estructural de la filosofía teórica, práctica y jurídica kantiana" Tesis doctoral, UNED 2013.

Hegel, Georg Wilhem Friedrich. Enciclopedia de las ciencias filosóficas, edición, introducción y notas de Ramón Valls Plana. Madrid: Editorial Alianza, 1997.

—. Fenomenología del espíritu, traducción de W. Roces. México: Fondo de Cultura Económica, 1966.

—. Introducción a la historia de la filosofía. Buenos Aires: Aguilar, 1977.

-. Principios de la filosofía del derecho, traducción de Juan Luis Vernal. Barcelona: Editorial Edhasa, 1999.

Herzog, Lisa. Inventing the market, Smith and Hegel political theory. Oxford: Oxford University Press, 2013

Horkheimer y Adorno. Dialéctica de la Ilustración. Madrid: Ed. Trotta, 1998.

Jiménez Redondo, Manuel. Introducción a Textos y contextos de Jürgen Habrmas. Barcelona: Ariel, 1996.

Kant, Immanuel. Crítica de la razón pura, prólogo, traducción, notas e índices por Pedro Rivas. Madrid: Santillana, 1997.

-. Crítica de la Razón Práctica, editado por Roberto R. Aramayo. Madrid: Alianza Editorial, 2000.

- Fundamentación de la metafisica de las costumbres, edición bilingüe y traducción por José Mardomingo. Barcelona: Editorial Ariel, 1996.

- Crítica del Juicio, edición y traducción por Manuel García Morente. Madrid: Espasa Calpe, 1997.

-. En torno al tópico: "Tal vez eso sea correcto en teoría, pero no sirve para la práctica" (1793). Ensayos sobre la paz, el progreso y el ideal cosmopolita. Madrid: Ediciones Cátedra, 2005.

-. Ideas para una historia universal en clave cosmopolita (1784). Ensayos sobre la paz, el progreso y el ideal cosmopolita. Madrid: Ediciones Cátedra, 2005.

- La metafísica de las costumbres, traducción y notas de Adela Cortina Orts y Jesús Conill Sancho. Madrid: Editorial Tecnos, 2008.

-. Sobre la paz perpetua (1795). Ensayos sobre la paz, el progreso y el ideal cosmopolita. Madrid: Ediciones Cátedra, 2005.

- Sobre un presunto derecho a mentir por filantropía, en Ensayos sobre la paz, el progreso y el ideal cosmopolita. Madrid: Editorial Tecnos, 2009. 
—. Der Streit der Facultäten. En KantsWerke, AkademieTextausgabe. Berlín: Walter de Gruyter, 1968. VII. [Traducción de Francisco J. Contreras Peláez en El Tribunal de la Razón].

Kervegan, J. Hegel, Carl Smith. Lo politico: entre especulación y positividad. Madrid: Escolar y mayo, 2007.

Muinelo Cobo, José Carlos. La invención del derecho en Aristóteles. Madrid: Dikynson, 2011.

Platón, Parménides, introducciones, traducciones y notas Ma ${ }^{\mathrm{a}}$. I. Santa Cruz, Á. Vallejo Campos, N. Luis Cordero. Madrid: Editorial Gredos, 1982.

Siep, Ludwig. La actualidad de la filosofía práctica de Hegel. Hegel y el holismo de la filosofía política. Bogotá: Universidad Externado de Colombia, 2007.

Ricoeur, P. "Historia de la idea de justicia I. La justicia según Aristóteles" Archipiélago 3 (1989).

Taylor, Charles, La libertad de los modernos, Buenos Aires: Amorrurtu editores, 2005.

—. Hegel y la sociedad moderna. México: Fondo de Cultura Económica, 1983.

Zubiri, Xavier, Los Problemas Fundamentales de la Metafisica Occidental. Madrid: Alianza Editorial, Fundación Xavier Zubiri, 1994.

Juan Manuel Espinosa Ares

Departamento Filosofía Jurídica

Facultad de Derecho

Universidad Nacional de Educación a Distancia

c/ Obispo Trejo

28040 Madrid (España)

https://orcid.org/0000-0001-7058-947X 
